\title{
O DESLOCAMENTO DA DINÂMICA POPULACIONAL POTENCIALIZADA PELO ESTADO: O CASO DO ESPÍRITO SANTO
}

\author{
Claudeci Pereira Neto
}

\begin{abstract}
Resumo: Os incentivos fiscais do Governo do Estado do Espírito Santo, através do INVEST-ES, e os benefícios fiscais e financeiros da União, por meio das políticas da SUDENE, contribuíram a partir dos anos 2000, para o deslocamento da dinâmica populacional para a parte norte do estado do Espírito Santo e mais fortemente para os municípios da faixa litorânea de Serra a São Mateus. Esse grupo de sete municípios, denominado "litoral dinâmico", tem apresentado taxas de variação geométrica anual da população bem acima das verificadas para a média do estado e para os demais 71 municípios. No período 1991-2000 ela alcançou taxas de 2,98 e, entre 2000-2016: 2,58. Para esses dois períodos a média estadual foi 1,96 e 1,57; e considerado o grupo de 71 municípios, 1,71 e 1,28, respectivamente.
\end{abstract}

Palavras-chave: INVEST-ES; ICMS; Sudene; Migração.

\section{THE DISPLACEMENT OF THE POPULATION DYNAMIC PERPETRATED BY THE STATE: THE CASE OF ESPÍRITO SANTO}

\begin{abstract}
Tax breaks of the Espírito Santo Government, by INVEST-ES, and tax and financial benefits, by means of SUDENE's policies, have contributed from the years 2000 for the population dynamics displacement to the northern part of the Espírito Santo state and more strongly to the coastline municipalities from Serra to São Mateus. This group of seven municipalities called "dynamic coastline" has presented rates of annual geometric variation of the population right above those verified for the state average and for the other 71 municipalities. In the period of 1991 to 2000 it reached rates of 2.98 and between 2000 and 2016: 2.58. For these two periods the state average was 1.96 and 1.57; and considering the group of 71 municipalities, 1.71 and 1.28 , respectively.
\end{abstract}

Keywords: INVEST-ES; ICMS; Sudene; Migration.

\footnotetext{
${ }^{1}$ Iniversidade Federal do Espírito Santo. claudecineto@hotmail.com
} 


\section{INTRODUÇÃO}

Em 1998, 28 municípios da parte norte capixaba foram incluídos na área da Superintendência de Desenvolvimento do Nordeste (Sudene), fazendo com que as empresas tivessem a possibilidade de usufruir de incentivos fiscais sobre o Imposto de Renda Pessoa Física (IRPJ) e benefícios financeiros federais, através de financiamento com taxas de juros subsidiadas.

Por seu turno, o Governo Estadual no intuito de atrair empreendimentos produtivos criou ferramentas de incentivos fiscais sobre o imposto sobre operações relativas à circulação de mercadorias e sobre prestações de serviços de transporte interestadual, intermunicipal e de comunicação (ICMS). Em 2003, lançou o Programa de Incentivo ao Investimento no Espírito Santo (INVEST-ES), em substituição aos Regimes Especiais de tributação que as empresas possuíam com as Secretaria de Estado da Fazenda (Sefaz), os chamados "contratos de gaveta".

O intrigante e perfeitamente compreensível pela lógica empresarial é o fato de que essas políticas do Governo Estadual reforçaram a implantação de empreendimentos na Região da Sudene, principalmente nos municípios com melhores infraestruturas urbanas, como Linhares, Colatina e São Mateus. A explicação se dá pelo acúmulo de benefícios sobre o IRPJ e sobre o ICMS numa mesma região em detrimento das demais. O Governo Estadual, apesar de conceder incentivos para todo território capixaba, não consegue interferir na localização dos empreendimentos (principalmente dos maiores), trazendo-os para os municípios não abrangidos pela Sudene e menos "desenvolvidos" economicamente.

Neste artigo, almeja-se demonstrar que o fluxo populacional para o norte do Espírito Santo, especialmente concentrado no litoral, foram também impulsionados pela concessão de benefícios fiscais, que ajudou a imprimir maior dinamismo econômico na região. Assim, se analisará o desempenho do INVEST-ES de 2003 a 2016 e sua forte concentração nos municípios da faixa litorânea de Serra a São Mateus e como se deu o incremento populacional no período de 1991 a 2016.

O primeiro tópico contém uma breve exposição sobre o papel do Estado fomentador de atividades econômicas. No seguinte, aborda-se a sistemática dos benefícios do INVEST-ES promovido pelo Estado. Por último, são apresentados e examinados os resultados do Programa e como se desenvolveu a dinâmica populacional no estado capixaba, tendo como pano de fundo também a sua inserção na Sudene a partir de 1998.

\section{O INTERVENÇÃO DO ESTADO}

O Estado é importante agente interventor capaz de interferir no fluxo migratório e na dinâmica demográfica, através de políticas de desenvolvimento em determinadas áreas. Sua política e seu poder de legislar interferem no espaço urbano de forma a atender empreendimentos privados e públicos, reservar áreas habitacionais para os diferentes níveis de classes sociais, conceder benefícios fiscais para projetos de investimento, além de doação de terrenos públicos, etc. 
Apesar de não se reduzir a fatores econômicos, "os estudos empíricos têm evidenciado que o determinante principal da migração é ordem econômica e traduz o desejo de segurança e de estabilidade. As pessoas migram, em geral, para melhorar o seu nível de vida e o de seus descendentes" (CASTIGLIONI, 2009a, p.51).

Joaquín Arango (2003, p.7) concorda que "[...] las disparidades económicas son, sin duda, condición necesaria para la mayor parte de los flujos migratorios, pero en ningún modo condición suficiente para que éstos se produzcan". Isso é corroborado pelos enormes desafios teóricos em meio a uma realidade em constante transformação e pela velocidade acelerada com que nascem novos determinantes do ato migratórios, sem precedentes na história das sociedades.

Com o "crescimento e amadurecimento" do atual modo de produção, provavelmente, algumas funções foram mudadas ou adequadas; "no entanto, a noção de que o capitalismo alguma vez funcionou sem o envolvimento estreito e firme do Estado é um mito que merece ser corrigido" (HARVEY, 2005, p. 90). Autores como Sposito (2014a; 2014b), Carlos (2015b; 2015c), Corrêa (2014) e Sampaio (2015) compartilham do pensamento de que o Estado não é neutro ao planejar suas políticas e seus investimentos.

Na visão de Paul Singer (1987) o Estado, em países de industrialização tardia, como o Brasil, foi e tem sido o grande indutor para assegurar a boa lucratividade dos empreendimentos, com subsídios creditícios, incentivos fiscais, manipulação de preços e do câmbio, cotas de mercado e de importação, entre outras coisas. Os arranjos institucionais alteram os preços relativos de determinadas empresas de alguns segmentos, tornando-as mais lucrativas; além de influenciar na instalação e relocalização de empresas.

De uma forma geral, os programa de 'desenvolvimento regional' nos países capitalistas tem dado ênfase ao desenvolvimento de infraestrutura de serviços nas áreas estagnadas - transporte, energia, comunicações etc. - e o oferecimento de incentivos econômicos, geralmente de caráter fiscal ou creditício, às empresas que se fixam em tais áreas. Desse modo, o quadro institucional é mais uma vez alterado na tentativa de se eliminar um desequilíbrio criado pelo próprio processo de industrialização institucionalmente condicionado (SINGER, 1987, p. 40).

O problema é que, segundo o autor, as tais políticas de desenvolvimento regional tendem a se concentrar em poucas cidades dentro de determinada região que o Estado almeja fomentar. De fato, as empresas tendem a eleger, dentro da região, municípios com melhor infraestrutura urbana, exceto quando buscam proximidade com matérias-primas e insumos ou quando são atraídas por municípios menores, que oferecem maiores vantagens, como doações de terrenos.

Singer (1987) discute as diferenças econômicas regionais, impulsionadas pelo processo de industrialização, como o motor das migrações internas e a configuração. No contexto da aglomeração espacial das atividades, as migrações internas "[...] não parecem ser mais que um mero mecanismo de redistribuição espacial da população que se adapta, em última análise, ao rearranjo espacial das atividades econômicas" (SINGER, 1987, p. 33). São as diferentes modalidades de industrialização que condicionam os diferentes fluxos migratórios.

No entanto, a análise da industrialização não pode se apartar dos condicionantes históricos que configuraram o modo de produção e localização industrial. Ao defender a determinação histórica das migrações internas, o autor 
defende "[...] a hipótese da existência de tipos historicamente definidos de migrações, condicionadas pela industrialização" (SINGER, 1987, p. 31).

Em verdade, como bem lembrado por Sposito (2014a, p.10), "a industrialização dá o 'tom' a urbanização contemporânea”, e o desejo de refletir sobre a sociedade não pode se furtar da análise conjunta dessas duas variáveis. $\mathrm{E}$ ainda acrescenta: "[...] entender a urbanização a partir do desenvolvimento industrial, é procurar entender o próprio desenvolvimento do capitalismo" (SPOSITO, 2014a, p.43).

Segundo Juan Elizaga (1980) as migrações internas são encaradas por boa parte da teoria econômica como mecanismo de ajuste aos desequilíbrios entre regiões. O fluxo se dá de regiões que recebem conotações negativas (rurais e/ou deprimidas) para regiões com certo grau de positivismo: urbanizadas, industrializadas e em desenvolvimento. Não obstante, o autor observa que as redes migratórias podem gerar fluxo de pessoas que não guarda relação automática com fatores de atração e sem correspondência com o equilíbrio, especialmente com o do mercado de trabalho. Nas palavras do autor, "[...] as relações de parentescos e amizade dos migrantes potenciais criam uma rede de vinculações que promove o fluxo migratório, muitas vezes independente das oportunidades reais oferecidas pelo lugar de destino" (ELIZAGA, 1980, p. 562).

\section{OS BENEFÍCIOS E A SISTEMÁTICA DO INVEST-ES NA MODALIDADE INDÚSTRIA}

O INVEST-ES tem como marco o Decreto $n^{\circ} 1.152-R$, de maio de 2003, que posteriormente foi revogado pelo Decreto $n^{\circ} 1.951-R$, de 25/10/2007. A vigência do INVEST-ES conferiu maior transparência na concessão de benefícios fiscais concedidos pelo Governo. Neste sentido, as empresas que possuíam regimes especiais vigentes (os chamados "contratos de gaveta") tiveram a possibilidade de migrar para o Programa.

As incertezas jurídicas e o desconforto na concessão de benefícios através de Decreto levou o Governo do Estado a protocolar em 27/06/2016, na Assembleia Legislativa, o Projeto de Lei $n^{\circ} 197 / 2016$, que se caracterizou por juntar os benefícios do Decreto $n^{\circ}$ 1.951-R, do INVEST-ES Indústria e da Resolução $n^{\circ} 496$, do INVESTES Importação. Aproveitando sua ampla base apoio na Assembleia, foi pedida urgência na apreciação do Projeto de Lei e em 29/06/2016 já tinha sido aprovado e transformado na Lei $n^{\circ}$ 10.550. Um dia depois foi sancionada e, em 01/07/2016, publicada no Diário Oficial do Espírito Santo (DIO-ES), com vigência a partir desta data.

As intenções do Governo ficaram bem claras na mensagem 184/2016, do Governador, que acompanhou o Projeto de Lei n 197/2016:

O Programa INVEST-ES tem como propósito ser um instrumento para a atração, promoção e consolidação de investimentos e a geração de emprego e renda para o Espírito Santo. Tradicionalmente instrumentos similares são utilizados pelos estados brasileiros e internacionalmente para atrair negócios. 
Incentivos compensam desvantagens comparativas possibilitando a justa concorrência com estados que possuem maior mercado consumidor, infraestrutura logística adequada às exigências do mercado, centros financeiros dinâmicos, fornecedores de bens e serviços mais numerosos, entre outros, como também possibilita a descentralização e diversificação da economia.

Considerando a realidade de crise econômica e incertezas pela qual passa o país, a estruturação do INVEST-ES por meio de uma Lei fornece ao investidor maior segurança para realizar seus investimentos no Espírito Santo.

Como contrapartida dos benefícios concedidos pelo Estado, que se expõe a seguir, a empresa apresenta um projeto de investimento, de implantação ou ampliação, e se compromete a gerar certo número de emprego. A Secretaria Estadual de Desenvolvimento (Sedes) abre um processo e o envia para o grupo técnico formado por funcionário (s) do Banco de Desenvolvimento do Espírito Santo (Bandes) e servidor (es) da Secretaria Estadual de Fazenda (Sefaz), para análise do projeto, da regularidade documental e fiscal da empresa. Posteriormente, o referido grupo técnico emite parecer e o encaminha para a apreciação do Comitê de Avaliação. Tal Comitê, não remunerado, é formado por titular e suplente das seguintes instituições: Sedes, Sefaz, Bandes, Secretaria de Estado da Agricultura, Abastecimento, Aquicultura e Pesca (Seag), Procuradoria Geral do Estado (PGE) e Secretaria de Estado de Controle e Transparência (Secont). Se aprovado o projeto, publica-se um resumo da Resolução no DIO-ES e a empresa tem 12 meses assinar o Termo de Acordo com a Sefaz (podendo ser prorrogado por igual período). Esse Termo se assemelha a um contrato com direitos e deveres. De um lado, a empresa se comprometendo a investir e a gerar empregos - conforme dispõe o projeto -, além de satisfazer obrigações tributárias assessórias e principais; de outro, o Governo do Estado, concedendo benefícios fiscais por 12 anos.

A partir da assinatura do citado Termo, a empresa pode diferir o pagamento do ICMS, na compra de máquinas e equipamentos destinados ao ativo imobilizado do parque industrial. Trata-se de uma postergação do pagamento do imposto para um momento futuro. De fato, a empresa não recolhe o imposto na compra e quando ela quiser alienar a terceiros pagará o imposto sobre o valor residual da máquina (valor de mercado). Provavelmente essa máquina terá um valor contábil reduzido em decorrência da depreciação acumulada.

Uma novidade trazida pela Lei $n^{\circ} 10.550$, no seu artigo $3^{\circ}$, inciso II, foi a possibilidade - também a partir da assinatura do Termo de Acordo - de isenção de ICMS nas compras de mercadorias ou bens destinados à construção civil dos empreendimentos. Essa era uma reivindicação antiga dos empresários.

Para que a empresa possa usufruir dos benefícios sobre o ICMS na compra de matérias-primas e insumos, e nas vendas internas e interestaduais, deve solicitar visita técnica para atestar a realização dos investimentos. Ela é realizada por funcionário do Bandes e servidor da Sedes. Essa constatação pode ser parcial ou total, ou seja, se a empresa investiu parte do previsto, mas com isso já consegue iniciar a operação, pode pedir uma visita para emissão de laudo de investimento parcialmente implantado. A partir da data de emissão do primeiro laudo (parcial ou total) a beneficiária pode fazer jus aos benefícios, abaixo citados, pelo prazo de 12 anos. No período futuro, quando concluir os investimentos, deve solicitar uma nova visita para emissão de laudo de investimento totalmente implantado. As alíneas 'c' e 
'e' do inciso I, o inciso III e a alínea 'a' do inciso IV, do art. 3, da Lei n 10.550/2016, constam os seguintes benefícios:

I - Diferimento do pagamento do ICMS:

c) incidente nas operações de importação do exterior de insumos e matérias-primas, destinados exclusivamente ao estabelecimento industrial importador, para o momento em que ocorrer a saída dos produtos resultante de sua industrialização, ressalvado o disposto na alínea "d".

e) incidente nas operações internas com matérias-primas e insumos, destinados exclusivamente a estabelecimento industrial vinculado ao INVEST-ES, para o momento em que ocorrer a saída dos produtos resultantes de sua industrialização.

III - crédito presumido, nas operações interestaduais, até o limite de setenta por cento do valor do imposto devido mensalmente [...].

IV - redução de base de cálculo do ICMS:

a) nas operações internas, até o limite de setenta por cento do seu respectivo valor $[\ldots]$.

Ao adquirir matérias-primas e insumos dentro do estado e no mercado internacional a empresa não recolherá o ICMS. Isso será feito somente quando vender a sua mercadoria resultante do processo produtivo. Num primeiro momento, isso melhora o fluxo de caixa da empresa.

Além disso, nas suas vendas, a empresa tem dois benefícios: crédito presumido nas operações interestaduais e redução de base de cálculo, nas operações internas. Explique-se a apuração deles com um exemplo para cada.

Suponha que em uma empresa, no período de apuração do ICMS, 40\% foram destinadas para outros estados. Presuma ainda que o crédito total de ICMS do período (excluído o crédito relativo às exportações) seja $\mathrm{R} \$ 1.000,00$. Aplicando o percentual das saídas para outros estados sobre esse crédito tem-se: $40 \% \times \mathrm{R} \$$ $1.000,00=R \$ 400,00$. Imagine também que o débito desse imposto nas vendas interestaduais seja $\mathrm{R} \$ 600,00$. Deste, subtrai-se o valor resultante do percentual das vendas aplicado sobre os créditos totais, que como se calculou acima é igual a $R \$$ 400,00 . Então encontra-se uma preliminar do imposto a recolher: $R \$ 600,00-R \$$ $400,00=\mathrm{R} \$ 200,00$. Entretanto, como a empresa possui o benefício do crédito presumido estabelecido no Termo de Acordo (exemplo: de 70\%), o valor efetivamente recolhido ao cofre estadual será: $R \$ 200-(70 \% \times R \$ 200,00)=R \$$ 60,00 . Essa sistemática pode ser visualizada na Figura 1.

Para o cálculo dos benefícios nas vendas dentro do estado, a empresa deve tempestivamente apurar o débito de ICMS, conforme exemplo da Figura 2. Conjecture que apenas uma mercadoria foi vendida durante o mês, dentro do Espírito Santo, por $\mathrm{R} \$ 10.000,00$. Essa seria a base na qual incidiria a alíquota de ICMS. Contudo, como a empresa possui um Termo de Acordo assinado com a Sefaz concedendo direito a $70 \%$ de redução de base de cálculo, ela deverá reduzir a base nesse percentual. Note que a alíquota agora incide sobre $30 \%$ do valor da mercadoria e, portanto, seu débito será $\mathrm{R} \$ 3.000,00 \times 17 \%=R \$ 510,00$, destacado na nota fiscal de venda e apurado no livro fiscal. 
Figura 1: Sistemática de apuração do ICMS a recolher com a aplicação do benefício do crédito presumido nas operações interestaduais

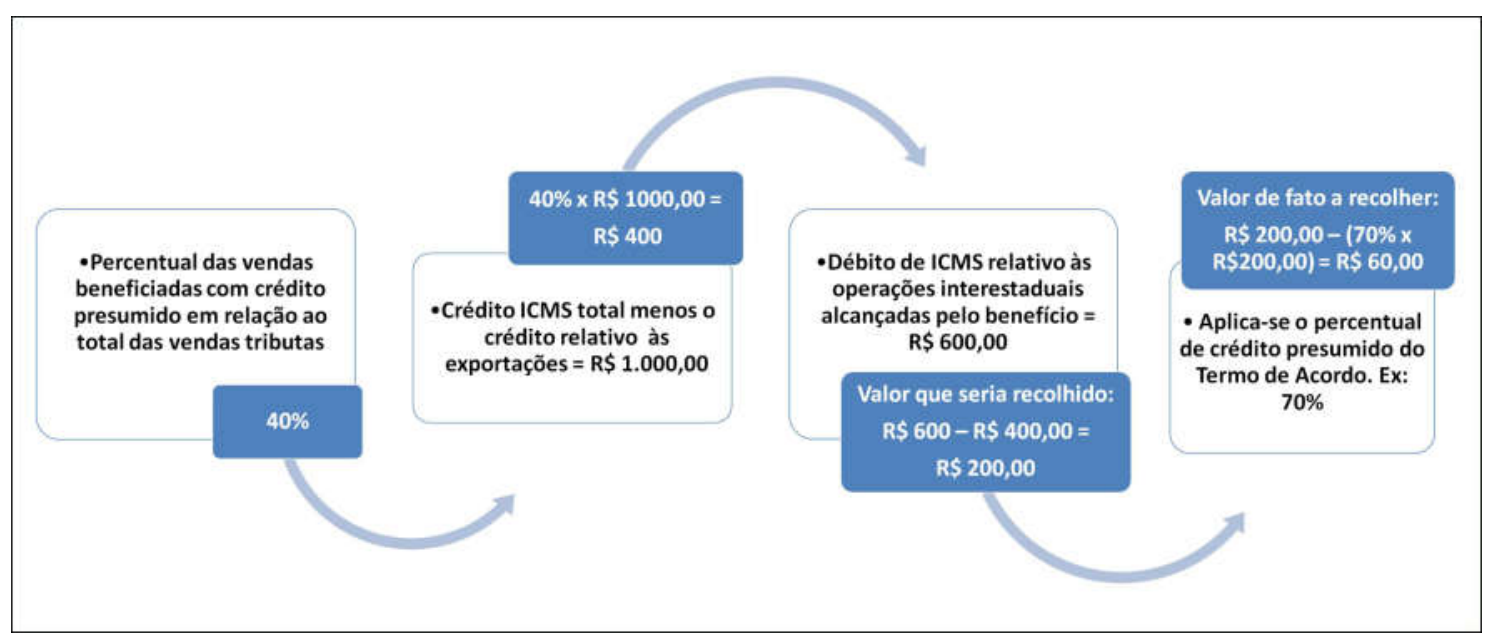

Fonte: Elaboração própria com base na Lei n 10.550/2016.

Ao final do período passa-se a apuração do crédito de ICMS. A empresa deve encontrar o percentual das vendas internas em relação ao total das vendas tributadas (por hipótese, 60\%) e aplicar sobre o crédito total, excluído os créditos referentes aos produtos exportados. No exemplo da Figura 2 será $60 \% \times \mathrm{R} \$$ $1.000,00=\mathrm{R} \$ 600,00$. Em seguida, sobre este valor, incide a mesma porcentagem de redução de base de cálculo disposta no Termo de Acordo, ou seja, $70 \%$. Encontra-se o montante de $\mathrm{R} \$ 600,00 \times 70 \%=\mathrm{R} \$ 420,00$. Este precisa ser retirado do valor crédito referente às operações internas, como calculado acima: $R \$ 600,00$. Seguindo isso, percebe-se um valor de crédito de $R \$ 600,00-R \$ 420,00=R \$$ 180,00. Para finalizar a sistemática, este precisa ser estornado do débito já apurado: $R \$ 510,00-R \$ 180,00=R \$ 330,00$. Destarte, este será o valor que a empresa irá recolher ao cofre estadual.

Historicamente, as empresas tem conseguido, no mínimo, o percentual de $70 \%$ tanto para crédito presumido como para redução de base de cálculo. Contudo, há previsão no artigo 19 da Lei 10.550/2016 para alíquota superior. E o artigo $5^{\circ}$ dispõe que o tratamento diferenciado pode ser em razão da natureza da atividade, da não similaridade com a produção estadual, da descentralização do desenvolvimento, de projetos que se instale em municípios com baixos indicadores socioeconômicos, e da competitividade com empreendimento similar localizado em outro estado. Verifica-se aí que o Comitê de Avaliação INVEST-ES possui ampla discricionariedade para julgar um projeto e decidir qual a alíquota conceder acima de 
$70 \%$, tanto para crédito presumido quanto para redução da base de cálculo. Contudo, esse percentual não tem ultrapassado $90 \%$ - concedidos para empresas que se instalam em municípios interioranos.

Existe outra fonte de discricionariedade dentro da redação da Lei $\mathrm{n}^{\circ}$ 10.550/2016. Trata-se do alcance do inciso VI, do art. $3^{\circ}$ : "outras modalidades de benefícios fiscais, desde que respeitados os limites e condições previstos nesta Lei $[\ldots] "$.

Figura 2: Sistemática de apuração do ICMS a recolher com a aplicação do benefício de redução de base de cálculo nas operações interestaduais

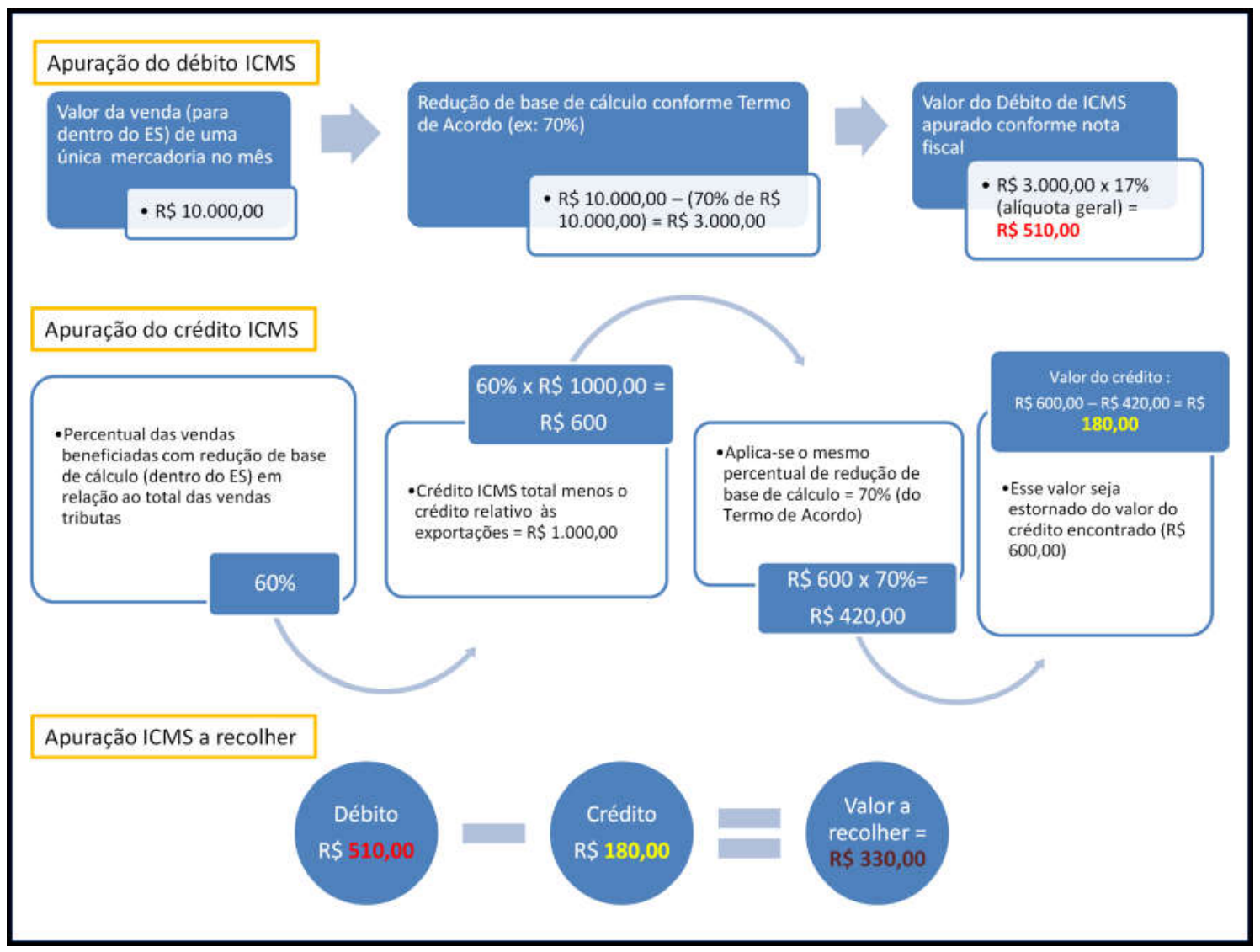

Fonte: Elaboração própria com base Lei no 10.550/2016.

De fato, este inciso tem sido usado, principalmente, para o governo capixaba se defender das barreiras criadas pelos outros estados contra benefícios fiscais concedidos no ES. Explique-se com um exemplo. Suponha que uma indústria enquadrada no INVEST-ES venda um produto de $\mathrm{R} \$ 1.000,00$ para uma revendedora em MG. Como aquela tem o diferimento na compra de matérias-primas e insumos (dentro do ES e no mercado internacional), não possui nenhum crédito. A alíquota interestadual de ICMS nessa operação é $12 \%=120,00$, que deveriam ser recolhidos ao cofre do ES. Contudo, isso não ocorre integralmente visto que ela tem o benefício do crédito presumido nas vendas interestaduais. De qualquer forma, em razão da não cumulatividade do imposto, a revendedora se credita de 120,00 e quando ela vender a mercadoria recolherá para o estado mineiro a diferença de valor entre o montante de ICMS gerado com a venda e o montante de seu crédito. Veja na 
Figura 3 que se a revendedora vender por $R \$ 1.200,00$, gerará um ICMS de $R \$$ 204,00, mas em razão dos créditos, somente recolherá a MG: R\$204,00 - R\$ $120,00=R \$ 84,00$.

Figura 3 - Sistemática de débito e crédito numa venda interestadual entre ES e MG.

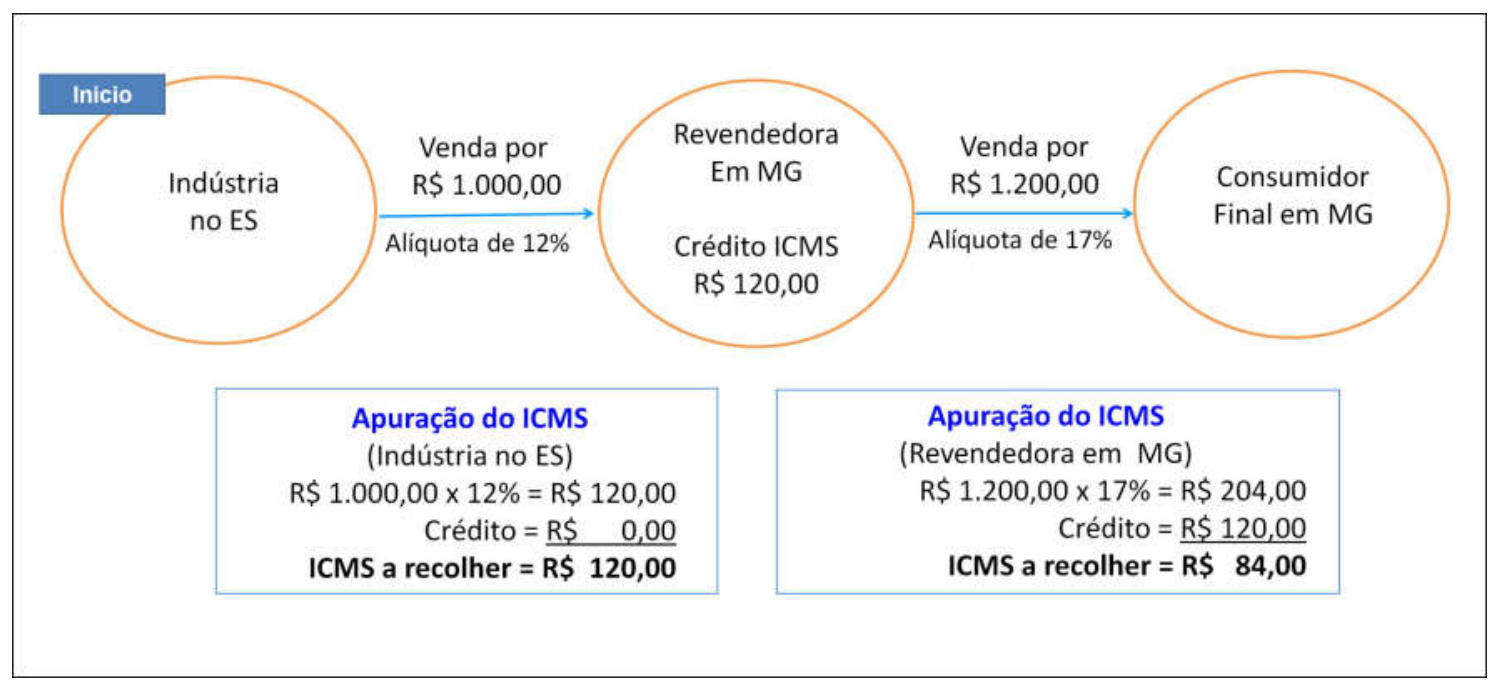

Fonte: Elaboração própria.

Numa transação de compra e venda normal, sem benefício, realmente o valor a ser recolhido para MG deveria ser $\mathrm{R} \$ 84,00$. Percebe-se, no entanto, que a indústria repassa $12 \%$ de ICMS ao seu produto, mas efetivamente ela não recolhe essa alíquota, em virtude do benefício do crédito presumido nas vendas interestaduais. No entanto, na nota fiscal de venda, a indústria destaca $12 \%$ de ICMS, gerando assim um crédito para a revendedora em MG. O Governo mineiro sabendo que a indústria capixaba tem benefícios (e portanto, efetivamente não recolhe a "alíquota cheia" ao ES), não aceita o crédito de $12 \%$ da revendedora. Popularmente, fala-se que MG está "glosando os créditos" do ES.

Assim, com o propósito de não conferir lacunas para MG deixar de aceitar os créditos provenientes de empresas "Investianas", o Comitê de Avaliação tem concedido que essas incluam nos Termos de Acordos uma ou mais empresas do grupo como distribuidoras. Assim, abre a possibilidade da beneficiária vender para elas seus produtos com incentivos. Ou seja, a indústria ao vender para a distribuidora do grupo dentro do estado usa o benefício da redução da base de cálculo, estorno de débito etc. Por outro lado, distribuidora não possui benefícios fiscais e é justamente ela que vende para revendedora em MG. Nesse caso, o estado de Minas Gerais não encontra respaldo para glosar os créditos da empresa revendedora mineira.

No final de 2012, com os rumores da convalidação, pelo Confaz, de todos os benefícios fiscais atualmente concedidos pelos estados, estabelecendo um prazo 
para seus términos, o Governo do Espírito Santo editou o Decreto $n^{\circ} 3.080-R$, acrescentando ao Decreto $\mathrm{n}^{\circ} 1951-\mathrm{R}$ a possibilidade de renovação de prazo dos benefícios por 12 anos. A Lei $n^{\circ}$ 10.550/2016 que revogou o Decreto $n^{\circ} 1951-R$ manteve essa possibilidade e ampliou seu alcance. Antes o benefício da redução da base de cálculo nas vendas internas não era renovável, mas uma alteração através da Lei $n^{\circ} 10.630$, de 28/03/2017, permitiu esse direito, desde que, de acordo com o $\S 2^{\circ}$-A, do artigo III, da Lei $\mathrm{n}^{\circ} 10.550$, "[...] requerido pelo interessado, com os motivos de fato e de direito em que se fundamentar, cabendo ao Comitê de Avaliação do INVEST-ES a análise do pedido". Para requerer a prorrogação dos outros benefício, a empresa deve protocolar carta na Sedes se comprometendo com a manutenção da média de empregados diretos dos últimos doze meses. Com a aprovação, pelo Comitê de Avaliação, publica-se uma resolução no Diário Oficial do ES. Posteriormente, a empresa pode solicitar a assinatura do Aditivo ao Termo de Acordo. A partir daí começa a fruir do prazo de 12 anos e a empresa abre mão do tempo remanescente de fruição do Termo de Acordo original.

\section{OS RESULTADOS DO INVEST-ES E A DINÂMICA DEMOGRÁFICA}

De 2003 a 2016, os projetos que continuavam enquadrados no INVEST-ES na modalidade indústria somavam 249. Destes, 149 eram de implantação de unidade industrial e 100 de ampliação/modernização.

Nota-se, pela Figura 3, a distribuição dos projetos nos 78 municípios que compõem o território do estado do Espírito Santo. Os municípios que mais receberam projetos foram os municípios de Serra (74) e Linhares (31). Em terceiro lugar aparece Cariacica com apenas 16 projetos. De fato, em Serra existe uma área industrial bem desenvolvida e a proximidade com a área portuária concede uma vantagem locacional para esse município. Já Linhares, além da prerrogativa de situar-se às margens da BR 101, é um dos municípios com melhor infraestrutura urbana dentre os situados na área de atuação da Sudene (Superintendência do Desenvolvimento do Nordeste) capixaba. Em 1998, 28 municípios, ou 52,8\% do território ao norte do estado, foram incluídos na abrangência desta Superintendência, o que beneficia empreendimentos que lá se encontram, ou que venham a se instalar, com redução de Imposto de Renda, depreciação acelerada de máquinas e equipamentos e subsídios nas taxa de juros dos financiamentos operacionalizados pelo Banco do Nordeste do Brasil.

Verifica-se ainda que dos 78 municípios, 42 não tiveram nenhum projeto enquadrado, 12 apresentaram apenas 1 projeto e outros 14 municípios de 2 a 5 projetos. Isso revela a dificuldade de atração de empreendimentos por parte da maioria dos municípios, que não possui boa estrutura urbana e logística e encontrase fora do corredor litorâneo, iniciado na Região Metropolitana da Grande Vitória (RMGV) e que se estende até São Mateus. A RMGV concentrou 115 projetos e R\$ 5,1 bilhões de investimento.

Ao longo desses catorze anos do Programa os projetos enquadrados somaram $\mathrm{R} \$ 12,8$ bilhões. No entanto, percebe-se uma concentração espacial no número e no porte dos projetos. Os municípios em que o montante dos investimentos dos projetos enquadrados foi acima de um bilhão de reais são apenas 
quatro: Aracruz ( $R$ \$ 3,5 bilhões), Serra ( $R$ \$ 3,3 bilhões), e Linhares ( $R$ \$ 1,2 bilhão) e Vitória (1,1 bilhão). Apesar de Serra possuir 76 projetos e Aracruz apenas 8, este apresenta valor de investimento um pouco maior que aquele. Em Aracruz, os projetos do Estaleiro Jurong, da Carta Industrial e da Imetame Logística, perfazem quase a totalidade dos investimentos para o município: $R \$ 3,4$ bilhões. Na capital, o valor de $R \$ 1,04$ bilhão é referente a três projetos de distribuição/transmissão de energia elétrica que atende a vários municípios capixabas. Esses investimentos constam em Vitória, pois os seus Termos de Acordo foram assinados pela matriz dessas empresas sediadas no município.

Figura 3: Número de projetos enquadrados e investimentos previstos, em R $\$$ milhões, no INVEST-ES Indústria, 2003 a 2016.

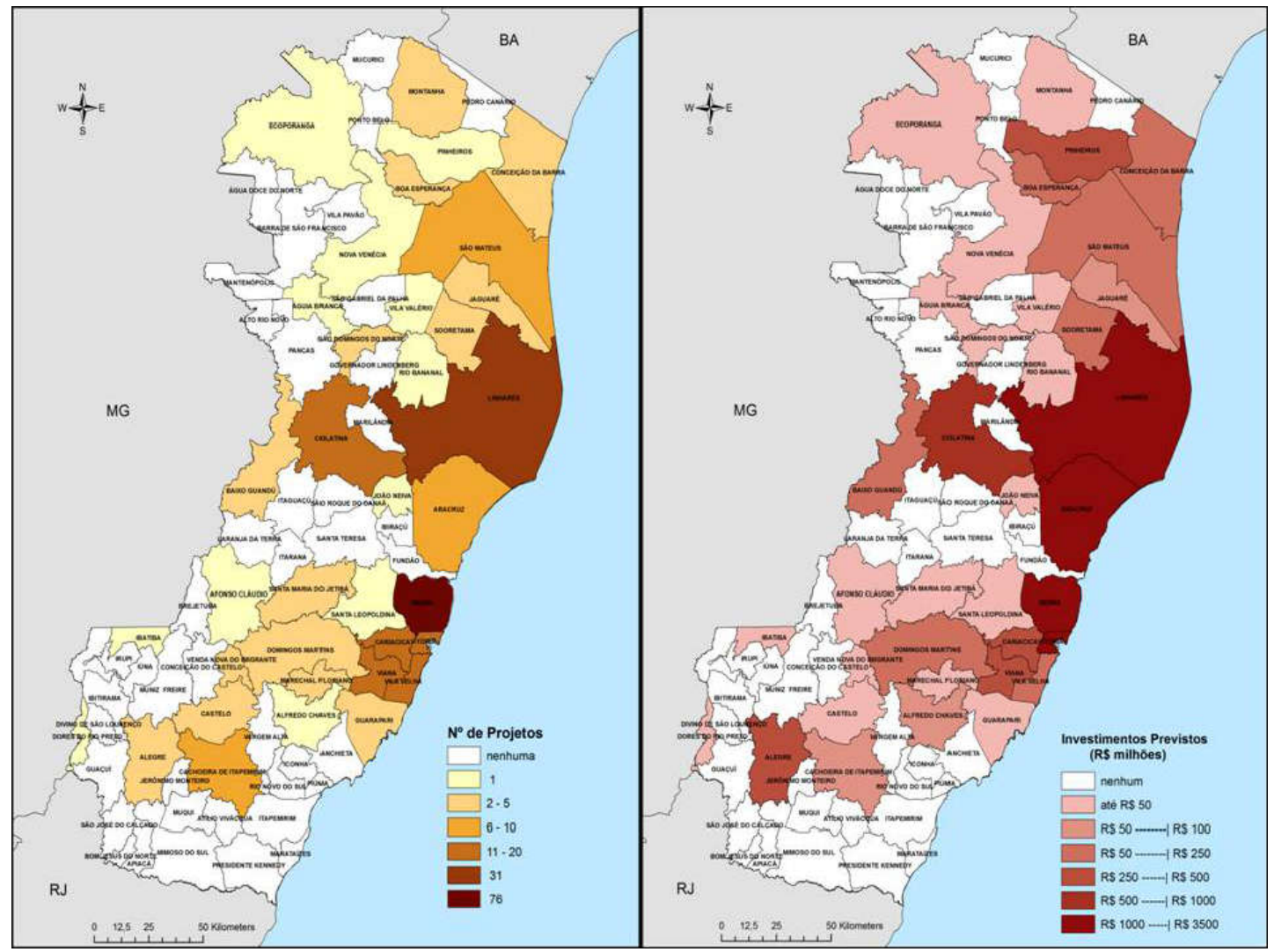

Fonte: Elaboração própria com base nos dados do BANDES.

Percebe-se que o deslocamento da dinâmica econômica foi acompanhado pelo crescimento populacional. A Figura 4 retrata a taxa geométrica de crescimento anual da população, ou seja, o incremento médio anual populacional. De 1991 a 2000 o maior dinamismo demográfico era comandado pelo litoral, e principalmente pela porção sul do estado. De 2000 a 2016 ocorre uma inversão de tendência em virtude da expansão econômica dos municípios litorâneos mais ao norte. Por outro lado, constata-se menor acréscimo populacional nos municípios do sul do estado, que são comandados por sua cidade mais importante economicamente, Cachoeiro de Itapemirim. 
Figura 4: Taxa de variação geométrica anual populacional, municípios do Espírito Santo, $1991-2000$ e $2000-2016$

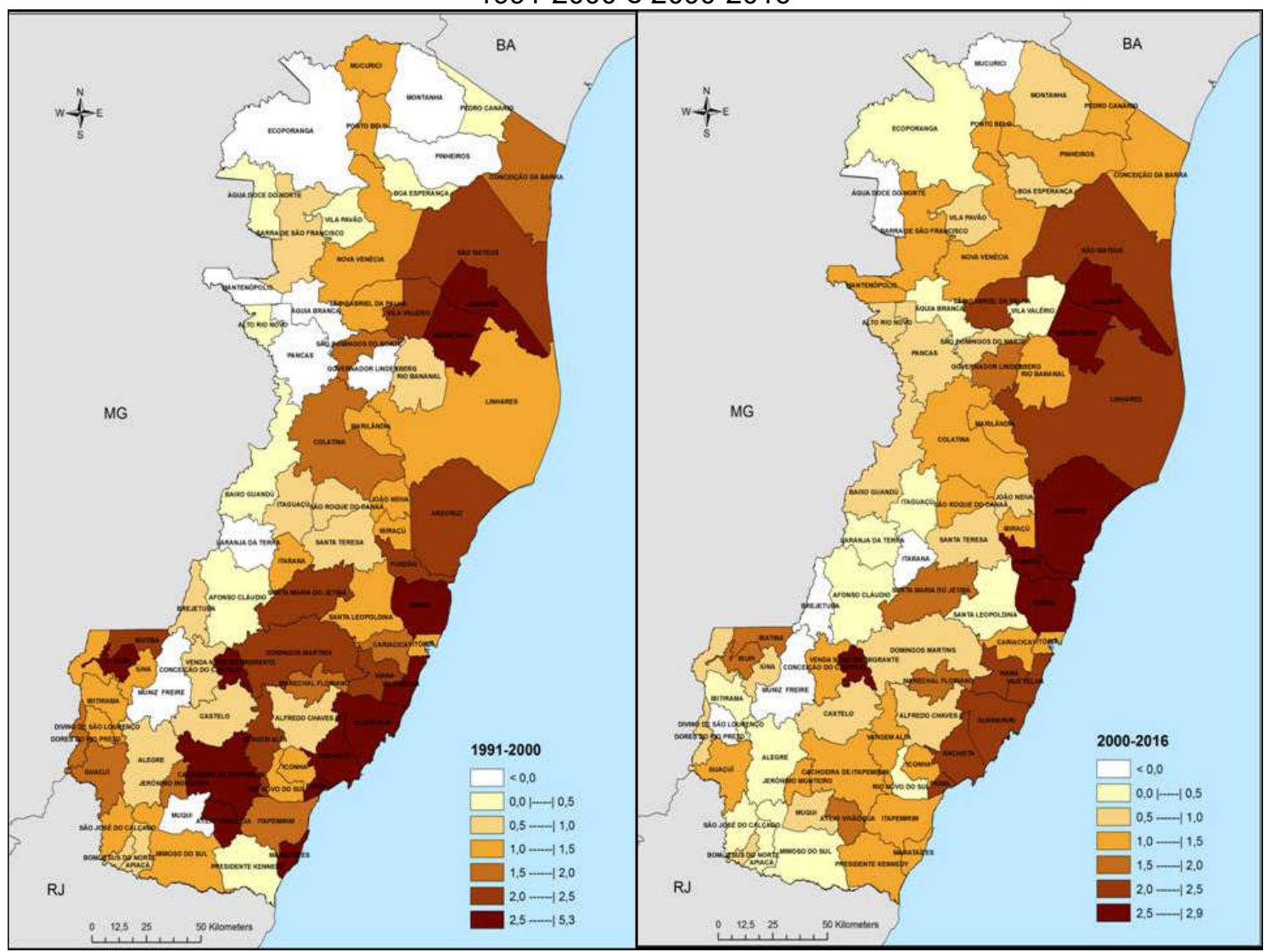

Fonte: Elaboração própria com base do PNUD e Estimativa da população do IBGE.

A fim de se analisar o deslocamento da dinâmica demográfica e tecer comparações dividiu-se o estado em dois grupos de municípios: os com maior dinamismo, denominado "litoral dinâmico", representados pelos municípios de Serra, Fundão, Aracruz, Linhares, Sooretama, Jaguaré e São Mateus; e os "demais municípios", representados pelos outros 71 municípios (Tabela 1).

De 1991 a 2000 a população do Espírito Santo aumentou em 496.614 pessoas, sendo $148.461(29,9 \%)$ no litoral dinâmico e 348.153 (70,1\%) nos demais municípios. No Censo de 2010 percebe-se a tendência do aumento de participação do litoral dinâmico no crescimento populacional do estado. No período intercensitário 2000-2010 ocorreu o incremento de 876.465 pessoas na população total do ES, sendo que os 7 municípios do litoral dinâmico corresponderam por $40,0 \%$ e os demais por $60,0 \%$. 
A estimativa para a população em 2016 trouxe essa tendência. No grupo litoral dinâmico, Serra é o município mais populoso e que obteve a maior variação absoluta e relativa da população entre 1991 e 2016. Neste período sua população passou de 222.934 para 494.109 pessoas, uma elevação de 271.175 pessoas ou $121,6 \%$. Somente esse incremento é maior que a população individual de 74 municípios capixabas em 2016, ficando abaixo de apenas 3 municípios da Região Metropolitana da Grande Vitória: Vila Velha (479.664), Vitória (479.664) e Cariacica (384.621).

Tabela 1: População total, variação absoluta e taxa de variação geométrica anual do Espírito Santo, 1991, 2000, 2010 e 2016.

\begin{tabular}{|c|c|c|c|c|c|c|c|c|c|c|}
\hline \multirow{2}{*}{$\begin{array}{c}\text { Espírito } \\
\text { Santo e } \\
\text { dois grupos } \\
\text { de } \\
\text { municípios }\end{array}$} & \multicolumn{4}{|c|}{ População Total } & \multicolumn{3}{|c|}{ Variação Absoluta } & \multicolumn{3}{|c|}{$\begin{array}{l}\text { Taxa de Variação } \\
\text { Geométrica Anual }\end{array}$} \\
\hline & 1991 & 2000 & 2010 & 2016 & $\begin{array}{c}1991-20 \\
00\end{array}$ & $\begin{array}{c}2000-20 \\
10\end{array}$ & $\begin{array}{c}2000-2 \\
016\end{array}$ & $\begin{array}{l}1991- \\
2000\end{array}$ & $\begin{array}{l}2000- \\
2010\end{array}$ & $\begin{array}{l}2000- \\
2016\end{array}$ \\
\hline $\begin{array}{l}\text { Espírito } \\
\text { Santo }\end{array}$ & $\begin{array}{r}2.600 .61 \\
8\end{array}$ & 3.097 .232 & 3.514 .952 & $\begin{array}{r}3.973 .69 \\
7\end{array}$ & 496.614 & 417.720 & $\begin{array}{r}876.46 \\
5\end{array}$ & 1,96 & 1,27 & 1,57 \\
\hline $\begin{array}{l}\text { Litoral } \\
\text { expandido }\end{array}$ & 491.522 & 639.983 & 806.979 & 961.818 & 148.461 & 166.996 & $\begin{array}{r}321.83 \\
5\end{array}$ & 2,98 & 2,35 & 2,58 \\
\hline Serra & 222.934 & 321.452 & 409.267 & 494.109 & 98.518 & 87.815 & $\begin{array}{r}172.65 \\
7\end{array}$ & 4,15 & 2,44 & 2,72 \\
\hline Fundão & 10.684 & 13.009 & 17.025 & 20.376 & 2.325 & 4.016 & 7.367 & 2,21 & 2,73 & 2,84 \\
\hline Aracruz & 52.526 & 64.637 & 81.832 & 96.746 & 12.111 & 17.195 & 32.109 & 2,33 & 2,39 & 2,55 \\
\hline Linhares & 101.299 & 112.617 & 141.306 & 166.491 & 11.318 & 28.689 & 53.874 & 1,18 & 2,30 & 2,47 \\
\hline Sooretama & 14.462 & 18.269 & 23.843 & 28.509 & 3.807 & 5.574 & 10.240 & 2,63 & 2,70 & 2,82 \\
\hline Jaguaré & 14.771 & 19.539 & 24.678 & 29.150 & 4.768 & 5.139 & 9.611 & 3,16 & 2,36 & 2,53 \\
\hline $\begin{array}{l}\text { São } \\
\text { Mateus }\end{array}$ & 74.846 & 90.460 & 109.028 & 126.437 & 15.614 & 18.568 & 35.977 & 2,13 & 1,88 & 2,11 \\
\hline $\begin{array}{l}\text { Demais } \\
\text { municí- } \\
\text { pios }\end{array}$ & $\begin{array}{r}2.109 .09 \\
6\end{array}$ & 2.457.249 & 2.707 .973 & $\begin{array}{r}3.011 .87 \\
9\end{array}$ & 348.153 & 250.724 & $\begin{array}{r}554.63 \\
0\end{array}$ & 1,71 & 0,98 & 1,28 \\
\hline
\end{tabular}

Fonte: Elaboração própria com base do PNUD e Estimativa da população do IBGE.

Percebe-se, pela Tabela 1, que a taxa de variação geométrica anual da população (1991-2000, 2000-2010, 2000-2016) dos municípios da região litoral dinâmico é maior que a observada para todo o estado (exceto para Linhares no período 1991-2000). Por outro lado, o grupo chamado "demais municípios" possui taxas inferior à média estadual. Isso confirma que o grupo litoral dinâmico tem se destacado no incremento populacional do Estado.

O município de Linhares é um dos casos que ratificam a relação entre concessão de benefícios fiscais e o deslocamento populacional. Entre 1991-2000 sua taxa de variação geométrica anual da população foi 1,18 , bem abaixo da registrada para o estado $(1,96)$. Contudo, a partir da década seguinte, com o maior dinamismo econômico em razão da atração de empreendimentos, passou a apresentar taxas de crescimento anuais bem acima da média estadual e próximas da média do grupo "litoral dinâmico".

Segundo BRASIL et al (2013), o Espírito Santo passou de uma situação de baixa absorção migratória nos anos de 1995/2000 para uma média absorção no período 2005/2010. A maioria dos imigrantes interestaduais é originária dos estados vizinhos (Minas Gerais, Bahia e Rio de Janeiro) e de São Paulo. 
O Censo 2000 e 2010 ao perguntar onde as pessoas residiam há 5 anos fornece pistas para entender como se projetou o fluxo migratório. Ao comparar os mapas com os dados desses dois Censos (Figura 5), nota-se que a parte norte capixaba passou a receber maior contingente de pessoas vindas de outros estados; e o sul não tem conseguido atrair, proporcionalmente ao norte, população. Depois dos municípios da RMGV, Linhares e São Mateus, no litoral norte, foram os que mais receberam pessoas de outros estados, 7.241 e 5.646 respectivamente. Extraindo do exame a RMGV pode-se melhor comparar e perceber a dinâmica populacional das regiões. No ano 2000 o número de pessoas que não residiam em 31/07/1995 nos municípios da Região da Sudene eram 23.317 e nos demais municípios (exceto os da RMGV) eram 27.776. No Censo de 2010, que perguntou onde as pessoas moravam em 31/07/2005, ocorreu uma inversão de tendência: a Sudene capixaba acolheu 35.634 pessoas de outros estados e os demais municípios, 27.385.

Figura 5: Pessoas de outros estados e que não residiam nos municípios do Espírito Santo em 31/07/1995 e em 31/07/2005.

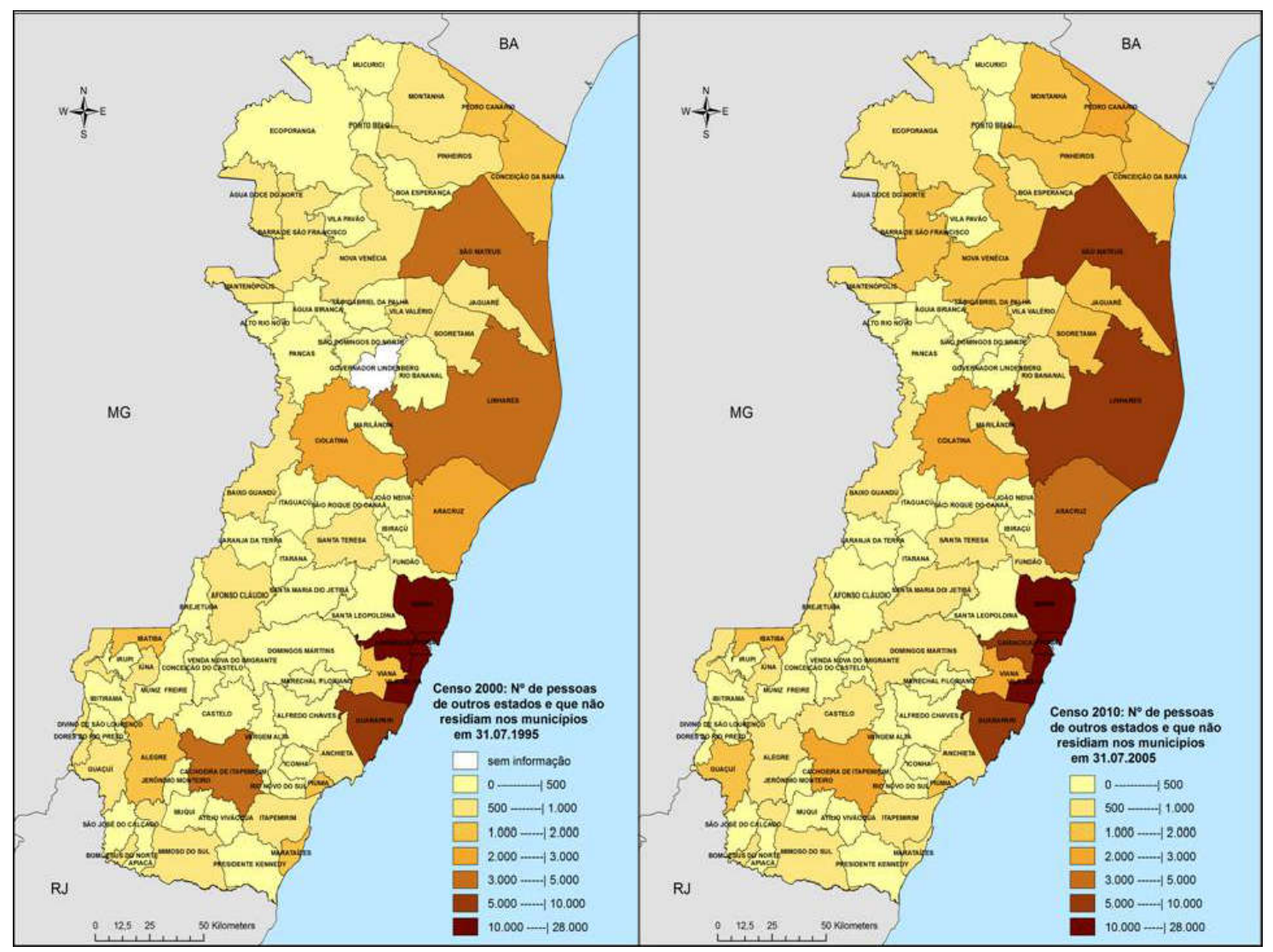

Fonte: Elaboração própria com base nos dados do IBGE, Censo 2000 e 2010.

Ao se examinar a variação, entre os Censos 2000 e 2010, dos residentes em cada município pela sua naturalidade, isto é, se nasceram no Espírito Santo ou em outros estados, percebe-se dois cenários. Quando se trata de migração intraestadual há um deslocamento para os municípios do litoral numa faixa que vai de Piúma a São Mateus. Os municípios de Linhares, São Mateus, Jaguaré e Sooretama, na porção norte, estão entre os 10 que aumentaram, acima de $20 \%$, o número pessoas residentes que nasceram no próprio estado, nesse período (Figura 6).

Em relação à migração interestadual a RMGV não apresentou crescimento percentual relevante (exceto Fundão) entre 2000 e 2010. Na Região da Sudene 
apenas 4 municípios tiveram variação negativa. Em contrapartida, na outra parcela do estado (exceto a RMGV), 19 municípios apresentaram redução no número de pessoas residentes e que nasceram em outras Unidades da Federação. A variação percentual dos residentes nascidos em outros estados nos anos 2000/2010 foi maior na região da Sudene, 16,5\%; acompanhado pela média dos demais municípios (extraindo os da RMGV), 12\%, e pela RMGV (10,5\%). Apesar da menor variação esta aumentou sua população de não capixabas em 37.283 , enquanto a região da Sudene observou um incremento menor, 22.187, mas bem acima do grupo dos demais municípios (12.030).

Figura 6: Variação percentual 2000-2010 dos residentes nascidos no Espírito Santo e dos residentes nascidos em outros estados, municípios do Espírito Santo.

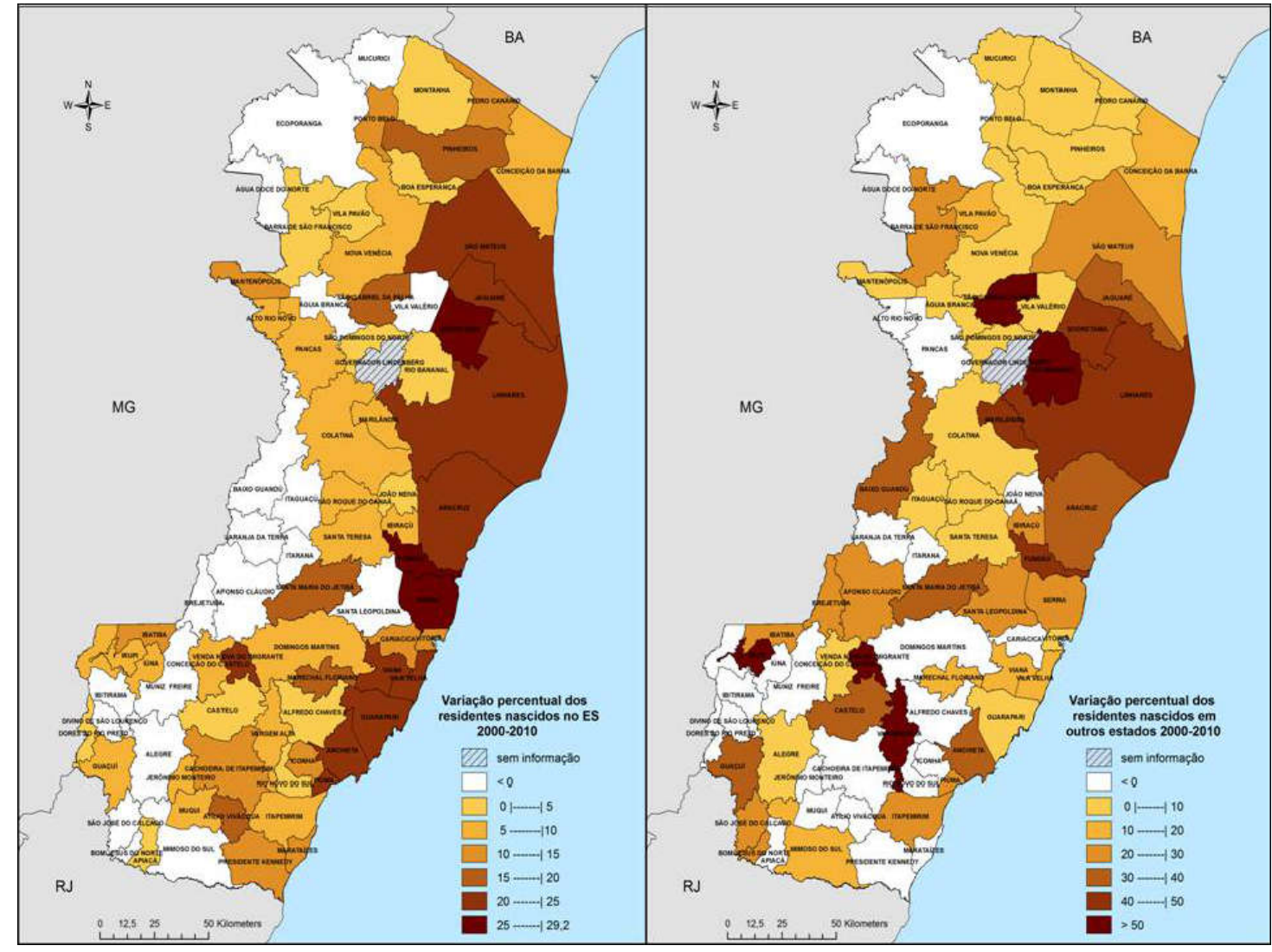

Fonte: Elaboração própria com base nos dados do IBGE, Censo 2000 e 2010.

\section{CONSIDERAÇÕES FINAIS}

As políticas de desenvolvimento regional com base na isenção ou redução de tributos tornou-se prática rotineira tanto em nível nacional como estadual. O Governo do Estado do Espírito Santo tem no INVEST-ES seu principal programa atração de empresas e manutenção de empresas. Desde a sua instituição, em 2003, até 2016, o INVEST-ES na modalidade indústria somou 249 projetos enquadrados, perfazendo um volume de investimento de R\$12,8 bilhões. Algo notório nesse Programa é a concentração espacial do número de empresas e do volume de investimento: somente o corredor litorâneo formado por Aracruz, Linhares e Serra, possui 113 projetos (o que corresponde a $\mathrm{R} \$ 8,0$ bilhões), ou seja, $63 \%$ do montante dos 
investimentos enquadrados. Dos 78 municípios capixabas, 42 não tiveram projetos enquadrados e, em 12 deles, apenas 1 projeto.

A despeito de todas as considerações legais, o benefício fiscal federal, através da Sudene, e o INVEST-ES, tem contribuído para um deslocamento da dinâmica econômica, mesmo que cadenciado, para municípios mais ao norte e com maior infraestrutura urbana e logística.

Esse dinamismo contribuiu para o incremento populacional especialmente na faixa litorânea de Serra a São Mateus e uma redução do ritmo de crescimento da parte sul do estado. Do acréscimo intersensitário de 496.614 pessoas, entre 19912000, o grupo "litoral dinâmico", representado por Serra, Fundão, Aracruz, Linhares, Sooretama, Jaguaré e São Mateus, teve participação de $29,9 \%$ e os demais municípios, 70,1\%. Já entre 2000 e 2010 o "litoral dinâmico" abarcou 40\% do incremento de 876.465 pessoas. Este grupo tem apresentado taxas de variação geométrica anual da população bem acima das verificadas para a média do estado e para os demais 71 municípios. No período 1991-2000 o "litoral dinâmico" alcançou taxas de 2,98 e, entre 2000-2016: 2,58. Para esses dois períodos a média do grupo dos demais 71 municípios foi 1,71 e 1,28, respectivamente.

Ao se comparar a dinâmica populacional dos 28 municípios da Sudene, no norte do Espírito Santo, com o restante dos municípios (retirando desse grupo a RMGV), percebe-se que o fluxo interestadual de pessoas teve uma inversão nos Censos de 2000 e 2010, ao perguntar aos residentes onde moravam a 5 anos atrás. Naquele Censo, 23.317 pessoas se dirigiram para os municípios da Sudene e 27.776 para "outros municípios" (grupo sem considerar a RMGV). Todavia, no Censo de 2010, a Sudene acolheu 35.634 pessoas e "outros municípios", 27.385. Além disso, a variação percentual dos residentes que nasceram em outros estados, nos anos 2000/2010, foi maior na região da Sudene, 16,5\%; acompanhado pela média dos "outros municípios" (12\%) e pela RMGV (10,5\%).

Assim, percebe-se que os benefícios fiscais do INVEST-ES, associados aos incentivos na área de atuação da Sudene no Espírito Santo, tem fomentado a dinâmica econômica nos municípios com melhor infraestrutura urbana e logística, que por sua vez tem atraído um maior fluxo de migrantes.

\section{REFERÊNCIAS}

ARANGO, Joaquim. La explicación teórica de las migraciones: luz y sombra. Migración y Desarrollo, Zacatecas, n. 1, p. 1-30, octubre 2003. BANCO DE DESENVOLVIMENTO DO ESPÍRITO SANTO (BANDES). Banco de
dados sobre o INVEST-ES. GECRE. 2017.

BRASIL. Constituição (1988). Constituição da República Federativa do Brasil. Brasília, DF: Senado Federal.

Disponível

Resolução n 13, de 25 de abril de 2012. Brasília, DF, Senado, 2012.

<http://legis.senado.gov.br/legislacao/ListaPublicacoes.action?id=264825>. Acesso em: 25 fev. 2017. 
BRASIL, G. et al. Dinâmica demográfica e mobilidade social no Espírito Santo. Nota técnica. In: Plano de Desenvolvimento Espírito Santo 2030. Vitória: DVF, 2013.

CARLOS, A. F. A. Da organização à produção do espaço no movimento do pensamento geográfico. In: CARLOS, A. F. A.; SOUZA, M. L. de; SPOSITO, M. E. B. (Org.); A produção do espaço urbano: agentes e processos, escalas e desafios. São Paulo: Contexto, 2014. p. 53-74.

Metageografia: ato de conhecer a partir da Geografia. In: CARLOS, A. F.

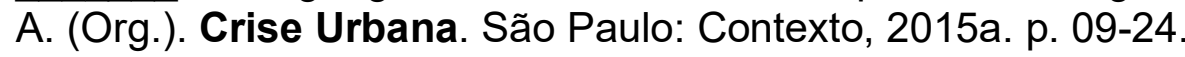

A reprodução do espaço urbano como momento da acumulação capitalista. In: Crise Urbana. São Paulo: Contexto, 2015b. p. 25-36.

A tragédia urbana. In: CARLOS, A. F. A.; VOLOCHKO, D.; ALVAREZ, I. P. (Org.). A cidade como negócio. São Paulo: Contexto, 2015c. p. 43-64.

CASTIGLIONI, A. H. Migration, urbanisation et développement: les cas de l'Espirito Santo - Brésil. Bruxelas: Ciaco, 1989.

Migração: abordagens teóricas. In: ARAGÓN, L. E. Migração Internacional na Pan-Amazônia. Belém: NAEA/UFPA, 2009a. v. 1. p. 39-57.

. Mudanças na estrutura demográfica do Espírito Santo ocorridas durante a segunda metade do século XX. Geografares (Vitória), v. 7, p. 93-109, 2009b.

CORRÊA, Roberto L. Estudos sobre a rede urbana. Rio de Janeiro: Bertrand Brasil, 2006.

Sobre agentes sociais, escala e produção do espaço: um texto para discussão. In: CARLOS, A. F. A.; SOUZA, M. L. de; SPOSITO, M. E. B. (Org.). A produção do espaço urbano: agentes e processos, escalas e desafios. São Paulo: Contexto, 2014. p. 41-52

DIÁRIO OFICIAL DO ESPÍRITO SANTO. Consultas ao Diário Oficial. 2014. Disponível em: <http://ioes.dio.es.gov.br/portal/visualizacoes/diario oficial>. Acesso em: 01 fev. 2017.

ELIZAGA, Juan C. Migrações internas: evolução recente e situação atual dos estudos. In: MOURA, Helio A. de (Coord.). Migração interna: textos selecionados. Fortaleza: BNB, 1980. p. 539-575.

ENVIRONMENTAL SYSTEMS RESEARCH INSTITUTE (ESRI). Programa ArcGis, versão 9.3. USA, 2008.

ESPÍRITO SANTO. Lei $\mathbf{n}^{\circ} \mathbf{7 . 0 0 0}$, de 27 de dezembro de 2001. Vitória, 2001. Disponível em: $<$ http://www.sefaz.es.gov.br/LegislacaoOnline/lpext.dll?f=templates\&fn=main-h.htm\& 2.0>. Acesso em: 14 fev. 2017.

Lei n 9.905, de 11 de setembro 2012. Vitória, 2012. Disponível em: <http://www.al.es.gov.br/antigo portal ales/images/leis/html/LO9905.html >. Acesso em: 05 mar. 2017.

Lei n 9.906, de 11 de setembro 2012. Vitória, 2012. Disponível em: <http://www.al.es.gov.br/antigo portal ales/images/leis/html/LO9906.html >. Acesso em: 05 mar. 2017. 
. Lei $\mathbf{n}^{\circ} \mathbf{1 0 . 5 5 0}$, de 30 de junho de 2016. Vitória, 2016. Disponível em: $<$ http://www.sefaz.es.gov.br/LegislacaoOnline//pext.dll//nfobaseLegislacaoOnline/leis/ 2016/lei\%20n.\%BA\%2010.550.htm?fn=document-frame.htm\&f=templates\&2.0>. Acesso em: 20 mai. 2017.

. Lei $\mathbf{n}^{\circ} \mathbf{1 0 . 6 3 0}$, de 28 de março de 2017. Vitória, 2017. Disponível em: <https://www.legisweb.com.br/legislacao/?id=341251>. Acesso em: 28 mai. 2017.

em:

Decreto $n^{\circ}$ 1951-R, de 25 de outubro de 2007. Vitória, 2007. Disponível

$<$ http://www.sefaz.es.gov.br/LegislacaoOnline//pext.dll/InfobaseLegislacaoOnline/decretos/2007/dec1951 r-atualizado.htm?fn=document-frame.htm\&f=templates\&2.0>. Acesso em: 02 mai. 2017.

Decreto $\mathbf{n}^{\circ}$ 3080-R, de 24 de agosto de 2012. Vitória, 2007. Disponível em:

$<$ http://www.sefaz.es.gov.br/legislacaoonline/lpext.dll/InfobaseLegislacaoOnline/decretos/2012/dec3080-r.htm?fn=document-frame.htm\&f=templates\&2.0>. Acesso em: 02 mai. 2017.

Decreto $\mathbf{n}^{\circ}$ 3473-R, de 19 de dezembro de 2013. Vitória, 2013. Disponível em: <http://www.bandes.com.br/Site/Dinamico/Show?id=31>. Acesso em: 03 abr. 2017.

Projeto de Lei $\mathrm{n}^{\circ}$ 197/2016. Vitória, 2016. Disponível em: <http://www.al.es.gov.br/novo portal/>. Acesso em: 05 jun. 2017.

HALLEY, B.M. O bairro e seus enredos: desatando a trama do lugar na cidade. XII Simpósio Nacional de Geografia Urbana. UERJ - Rio de Janeiro. 18 a 22 nov. 2013. 21p.

HARVEY, D. A produção capitalista do espaço. São Paulo: Annablume, 2005.

. Os limites do capital. São Paulo: Boitempo, 2013.

Cidades Rebeldes: do direito à cidade à revolução urbana. São Paulo: Martins fontes, 2014.

INSTITUTO BRASILEIRO DE GEOGRAFIA E ESTATÍSTICA (IBGE). Estimativa da população. Disponível em: $<$ http://www.ibge.gov.br/home/mapa site/mapa site.php\# populacao>. Acesso em: 02 mar. 2017.

Banco de dados agregados (Sidra). Disponível em: <https://sidra.ibge.gov.br/home/pms/brasil>. Acesso em: 10 mar. 2017.

INSTITUTO JONES DOS SANTOS NEVES (IJSN). Base de dados: dados socioeconômicos. 2014. Disponível em: <http://www.ijsn.es.gov.br/>. Acesso em: 03 mar. 2017.

PROGRAMA DAS NAÇÕES UNIDAS PARA O DESENVOLVIMENTO (PNUD). Atlas de Desenvolvimento Humano no Brasil (ADHB), 2013. Disponível em: <http://www.atlasbrasil.org.br/2013/pt/consultal>. Acesso em: 18 abr. 2017.

SAMPAIO. R. A. A violência do processo de urbanização. In: CARLOS, A. F. A. (Org.). Crise Urbana. São Paulo: Contexto, 2015. p. 55-84.

SINGER, Paul. Economia política da urbanização. 11. ed. São Paulo:Brasiliense, 1987. 
SPOSITO, M. E. B. O desafio metodológico da abordagem interescalar no estudo de cidades médias no mundo contemporâneo. Cidades, v.3, n.5, 2006, p. 143-157.

. Capitalismo e urbanização. 16. ed. São Paulo: Contexto, 2014a.

A produção do espaço urbano: escalas, diferenças e desigualdades socioespaciais. In: CARLOS, A. F. A.; SOUZA, M. L. de; SPOSITO, M. E. B. (Org.). A produção do espaço urbano: agentes e processos, escalas e desafios. São Paulo: Contexto, 2014b. p. 123-146. 